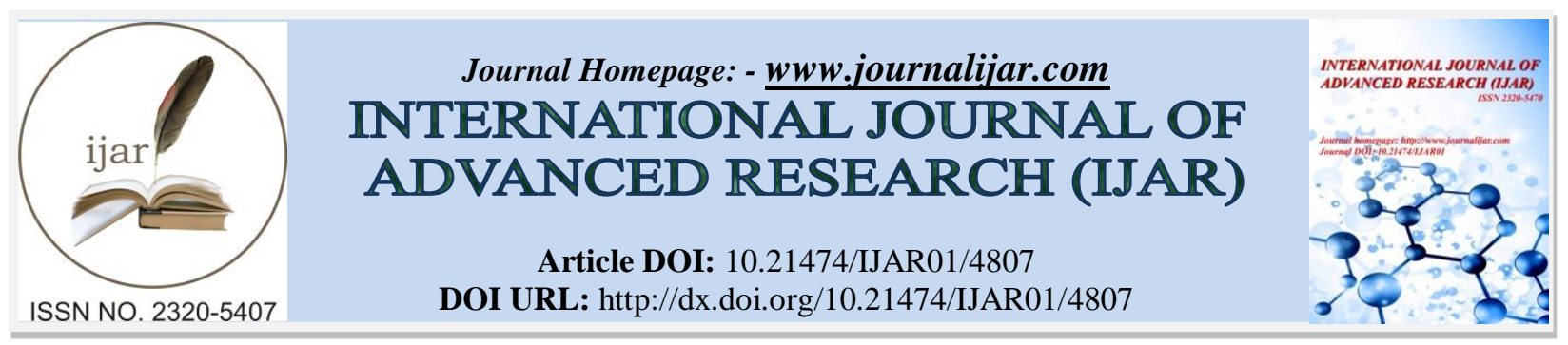

RESEARCH ARTICLE

\title{
CHARACTERIZATION OF RENAL STONES BY USG AT TERTIARY CARE CENTRE IN NORTH WESTERN RAJASTHAN.
}

\author{
MD. Khizer Razak ${ }^{1}$, Deepika Meena ${ }^{2}$ and G L Meena ${ }^{1}$. \\ 1. Department of Radiodiagnosis, SP Medical College \& Associate Group of PBM Hospitals, Bikaner. \\ 2. Rajasthan Dental College Jaipur.
}

\section{Manuscript Info}

(.........................

Manuscript History

Received: 10 May 2017

Final Accepted: 12 June 2017

Published: July 2017

Key words:-

Renal Stones, Ultrasound, Modalities.

\section{Abstract}

Background: Urinary tract stones are common, with a lifetime incidence of up to $12 \%$ and recurrence rates of up to $50 \%$.

Methods: This study was performed in Department of Radiology in sardar patel medical college,bikaner, in the period ranged (August 2016- December 2016), included 50 subjects (36 male and 14 female) with age range between from 17 to 70 .

Results: $44 \%$ of renal stone cases detected by USG. $8 \%$ of ureter stone case detected by USG.

Conclusion: U/S were found to be good modalities for depicting renal stones, U/S are the first line of choice in diagnosis of renal calculi.

Copy Right, IJAR, 2017,. All rights reserved.

\section{Introduction:-}

Urinary tract stones are common, with a lifetime incidence of up to $12 \%$ and recurrence rates of up to $50 \%$. In diagnostic and treatment algorithms, stone burden is the most important factor to consider and forms the basis of all clinical decision making ${ }^{1}$. Thus, accurate measurement of all calculi is crucial. Since its introduction ${ }^{2}$, unenhanced helical computed tomography (CT) has replaced intravenous urogram and is now regarded as the reference standard in the work-up of renal colic, owing to its high sensitivity and specificity. Apart from being the diagnostic standard, CT has the advantage of providing detailed anatomical information, can identify secondary signs of stone passage, and is useful for ruling out alternate pathologies in cases of diagnostic uncertainty. Despite the advantages of unenhanced CT, ultrasound (US) is also commonly used as a diagnostic tool in the management of urolithiasis. US is recognized to be both less sensitive and specific than CT; however, it is commonly available, inexpensive to operate and poses no risk of radiation exposure. In many cases, renal and ureteric calculi are incidentally diagnosed in the workup of other conditions. It has been reported that US may detect stones as small as $0.5 \mathrm{~mm}$ under optimal conditions. For these reasons, some centers may still use US in the initial work-up of renal colic ${ }^{3}$.Up to date, there has been little direct comparison of the accuracy and reliability of US compared with CT in sudan.Non-contrast spiral CT is presently more extensively used for the diagnosis of urolithiasis, especially in the setting of acute flank pain in adult patients . However, there is little data published over the use of spiral CT in pediatric urolithiasis. The presenting symptoms of children with stone disease are neither characteristic nor predictable and range from none to sepsis. Thus in pediatric patients with signs and symptoms suggestive of stone disease, radiologic studies are necessary for making an accurate diagnosis.Classically kidney, ureter and bladder plain films (KUB), ultrasound (US) and intravenous urography (IVU) have been utilized for this purpose. However, very little information exists in literature evaluating the accuracy of these modalities in the diagnosis of stones in the pediatric population. Given that the imaging of stones in children with conventional techniques has generally been non-satisfactory due to 
problems related to intestinal gas and smaller stone size in children, one may expect that spiral CT would be very beneficial for this age group.

\section{Materials and Methods:-}

This study was performed in Department of Radiology in sardar patel medical college,bikaner, in the period ranged (August 2016- December 2016), included 50 subjects (36 male and 14 female) with age range between from 17 to 70. They were selected from patients who had been referred for USG in PBM hospital. The variables that collected from each subject include:, USG findings, site of the stone, gender, age ,and body habitus.

\section{Results:-}

This data shows USG finding included 50 patients analyzed in tables and diagrams which showed below:

Table 1:- Shows USG in detection of affected side

\begin{tabular}{|c|c|}
\hline Affected site & No. of patients \\
\hline Left & 6 \\
\hline Right & 6 \\
\hline Both & 10 \\
\hline Nil & 28 \\
\hline Total & 50 \\
\hline
\end{tabular}

Table 2:- shows USG finding in detection of site of the stone

\begin{tabular}{|c|c|}
\hline Site of stone & No. of patients \\
\hline Kidney & 18 \\
\hline Ureter & 4 \\
\hline Nil & 28 \\
\hline Total & 50 \\
\hline
\end{tabular}

Table 3:-.shows USG in detection of stone according to size in the kidney

\begin{tabular}{|l|l|l|l|l|}
\hline Modality & Less than 5 mm & More than 5 mm & Total & Percentage \\
\hline Ct scan & 8 & 14 & 22 & $44 \%$ \\
\hline
\end{tabular}

Table 4:-shows USG in detection of stone according to size in the ureter

\begin{tabular}{|l|l|l|l|l|}
\hline Modality & Less than $5 \mathrm{~mm}$ & More than 5 mm & Total & Percentage \\
\hline Ct scan & 0 & 4 & 4 & $8 \%$ \\
\hline
\end{tabular}

\section{Discussion:-}

The present results agree with studied done by(Yilamz et al, and Oner et al) ${ }^{5,6} 56 \%$ of patients in studied sample are aged from 21-41 years old and they are mostly affected by renal stone, while $34 \%$ of patients are over 40 years U/S showed that both sides are affected equally. U/S showed that $44 \%$ of total cases were affected with stones in the Kidney, while ureteric stones $(8 \%)$. U/S is non-invasive, inexpensive and radiation free, so it is preferred by some radiologists as the initial method for evaluation of the renal stones. However, U/S is considered to be of limited value in demonstrating pathological conditions of the ureter ${ }^{7}$. All patients with ureterolithiasis described had some degree of uretero-hydronephrosis, hence U/S was able to follow the ureter to the level of the stone and demonstrate the exact nature of the obstructing lesion. An intraluminal echogenic focus with acoustic shadowing was clearly depicted in all cases. Technical problems might occur in assessing the ureter when the stone is in the middle third, an area often obscured by bowel gas so this problem solved by compressing the area to be examined and changing the patient's position. Dalla Palma ${ }^{8}$ evaluated 120 patients with renal colic using U/S and plain radiographs. U/S was classified as positive for ureteric colic in the study when calculi or hydronephrosis were present.

\section{Conclusion:-}

U/S were found to be good modalities for depicting renal stones, U/S are the first line of choice in diagnosis of renal calculi. 


\section{References:-}

1. Teichman JM. Clinical practice. Acute renal colic from ureteral calculus. N Engl J Med. 2004;350:684-693.

2. Smith RC, Rosenfield AT, Choe KA, et al. Acute flank pain:comparison of non-contrast-enhanced CT and intravenous urography. Radiology. 1995;194:789-794.

3. Catalano O, Nunziata A, Altei F, et al. Suspected ureteral colic: primary helical CT versus selective helical CT after unenhanced radiography and sonography. AJR Am J Roentgenol. 2002;178: 379-387.

4. Smergel E., Greenberg S.B., Crisci K.L., Salven J.K.: CT urograms in pediatric patients with ureteral calculi: do adult criteria work? Pediatr Radiol, 2001, 31: 720-723.

5. S. Yilmaz, T. Sindel, G. Arslan, C. Özkaynak, K. Karaali, A. Kabaalioğlu and E. Lüleci ,comparison of spiral CT, US and IVU in the detection of ureteral calculi, European Radiology Volume 8, Number 2, , 1997, 212 217.

6. S. Oner, A. Oto, S. Tekgul, M. Koroglu, M. Hascicek, A. Sahin and O. Akhan,Comparison of Spiral CT and us in the evaluation of pediatric urolithiasis, JBR-BTR, 2004, 87: 219-223.

7. Myers M.T., Elder J.S., Sivit C.J., Applegate K.E.: Unenhanced helical CT in evaluation of urinary tract in children and young adults following urinary tract reconstruction: comparison with sonography. Pediatr Radiol, 2001, 31: 135-139.

8. Strouse P.J., Bates D.G., Bloom D.A.,Goodsitt M.M.: Non-contrast thin section helical CT of urinary tract calculi in children. Pediatr Radiol, 2002, 32: 326-332. 